\title{
An Immunocytochemical Study of Glycine Receptor and GABA in Laminae I-III of Rat Spinal Dorsal Horn
}

\author{
K. Mitchell, R. C. Spike, and A. J. Todd \\ Department of Anatomy, University of Glasgow, Glasgow G12 8QQ, United Kingdom
}

\begin{abstract}
In order to provide information about the function of glycine in the superficial three laminae of the rat dorsal horn and the possible coexistence of glycine and GABA at synapses in this region, we have carried out a combined study involving preembedding immunocytochemistry with a monoclonal antibody to the glycine receptor and postembedding immunocytochemistry with antiserum to fixed GABA. Glycine receptor-like immunoreactivity was present at axodendritic and axosomatic synapses in all three laminae, and at dendrodendritic synapses in lamina II. Although axons that formed axoaxonic synapses were often presynaptic at immunoreactive axodendritic synapses (and thus probably contained glycine), the axoaxonic synapses themselves did not show glycine receptor-like immunoreactivity. Many of the profiles that were presynaptic at glycine receptor-immunoreactive synapses showed GABA-like immunoreactivity.

These results suggest that glycine acts as a postsynaptic inhibitory transmitter at various types of synapses in laminae I-III, and that it may coexist with GABA at many synapses in this region. However, it appears that while glycine and GABA may both be released at axoaxonic synapses, either glycine does not act as a transmitter at these synapses, or else it acts at an atypical receptor that was not recognized by the antibody used in this study.
\end{abstract}

[Key words: glycine receptor, GABA, spinal cord, dorsal horn, axoaxonic synapse, immunocytochemistry]

It is generally accepted that glycine acts as an inhibitory neurotransmitter in the mammalian spinal cord. Glycine is present in high concentrations in the spinal gray matter (Aprison and Werman, 1965), has a depressant action on spinal neurons that is antagonized by strychnine (Curtis et al., 1968), is released by a calcium-dependent mechanism (Hopkin and Neal, 1970), and is taken up by high-affinity transport (Neal, 1971). Glycine is thought to act by generating inhibitory postsynaptic potentials as a result of increasing chloride conductance (Barker and Nicoll, 1973). The anatomical localization of glycinergic systems in the spinal cord was initially examined by using radiolabeled glycine or strychnine combined with autoradiography, but recently antisera to fixed glycine and monoclonal antibodies to the postsynaptic glycine receptor have been developed (Pfeiffer et al.,

\footnotetext{
Received July 14, 1992; revised Nov. 9, 1992; accepted Dec. 8, 1992.

We thank Dr. P. Somogyi for his generous gift of GABA antiserum and Mr. D. Russell, Mr. R. Kerr, Miss C. Morris, and Miss M. Hughes for excellent technical assistance. This work was supported by a grant from the Wellcome Trust.

Correspondence should be addressed to Dr. A. J. Todd at the above address.

Copyright (C) 1993 Society for Neuroscience 0270-6474/93/132371-1 1\$05.00/0
}

1984; Campistron et al., 1986; Ottersen and Storm-Mathisen, 1987; Wenthold et al., 1987; van den Pol and Gorcs, 1988), and these have been used in immunocytochemical studies.

Within the dorsal horn, glycine-like immunoreactivity (-LI) is present in some neuronal cell bodies, dendrites, and axons (Campistron et al., 1986; Ottersen and Storm-Mathisen, 1987; van den Pol and Gorcs, 1988; Todd, 1990; Todd and Sullivan, 1990 ) and there is general agreement that these are concentrated in the deeper laminae (III-V) and present in smaller numbers in laminae I and II. Detectable glycine-LI is thought to represent elevated concentrations of glycine, which are present in neurons that use it as a transmitter, and is therefore used as a marker for presumed glycinergic neurons (Ottersen, 1989). Todd and Sullivan (1990) carried out a postembedding study of glycineLI on semithin sections of rat spinal cord and estimated that the proportions of immunoreactive neurons in laminae I, II, and III were $9 \%, 14 \%$, and $30 \%$, respectively. In addition, they found that glycine-LI was virtually restricted to neurons that also showed GABA-LI and suggested that the two inhibitory amino acid transmitters coexisted in many neurons within the dorsal horn.

Todd (1990) examined the ultrastructure of glycine-immunoreactive profiles within the superficial dorsal horn of the rat and reported that, while glycine-immunoreactive axons most frequently formed axodendritic and axosomatic synapses, they also formed some axoaxonic synapses and, in addition, glycineLI was present in some presynaptic dendrites. Since the synaptic arrangements involving glycine-LI were very similar to those that have been described for glutamic acid decarboxylase (GAD)or GABA-immunoreactive axons and dendrites (McLaughlin et al., 1975; Barber et al., 1978; Carlton and Hayes, 1990; Todd and Lochhead, 1990), it was suggested that elevated levels of glycine and GABA coexisted in many presynaptic structures and that most of these were derived from neurons with cell bodies located in laminae I-III. While the involvement of glycine in axodendritic, axosomatic, and dendrodendritic synapses would be compatible with a role in postsynaptic inhibition, the finding of glycine-LI in the presynaptic axons at axoaxonic synapses was unexpected and suggested a possible function for glycine in presynaptic inhibition, although there is apparently no pharmacological evidence for this (Levy, 1977). However, if glycine and GABA coexist in these axons, it is possible that only GABA is acting at axoaxonic synapses to produce presynaptic inhibition. In order to provide further information about the types of synapses at which glycine acts as a neurotransmitter, we have carried out a preembedding immunocytochemical study of rat dorsal horn with a monoclonal antibody to a component of the glycine receptor. In addition, this has been combined with 


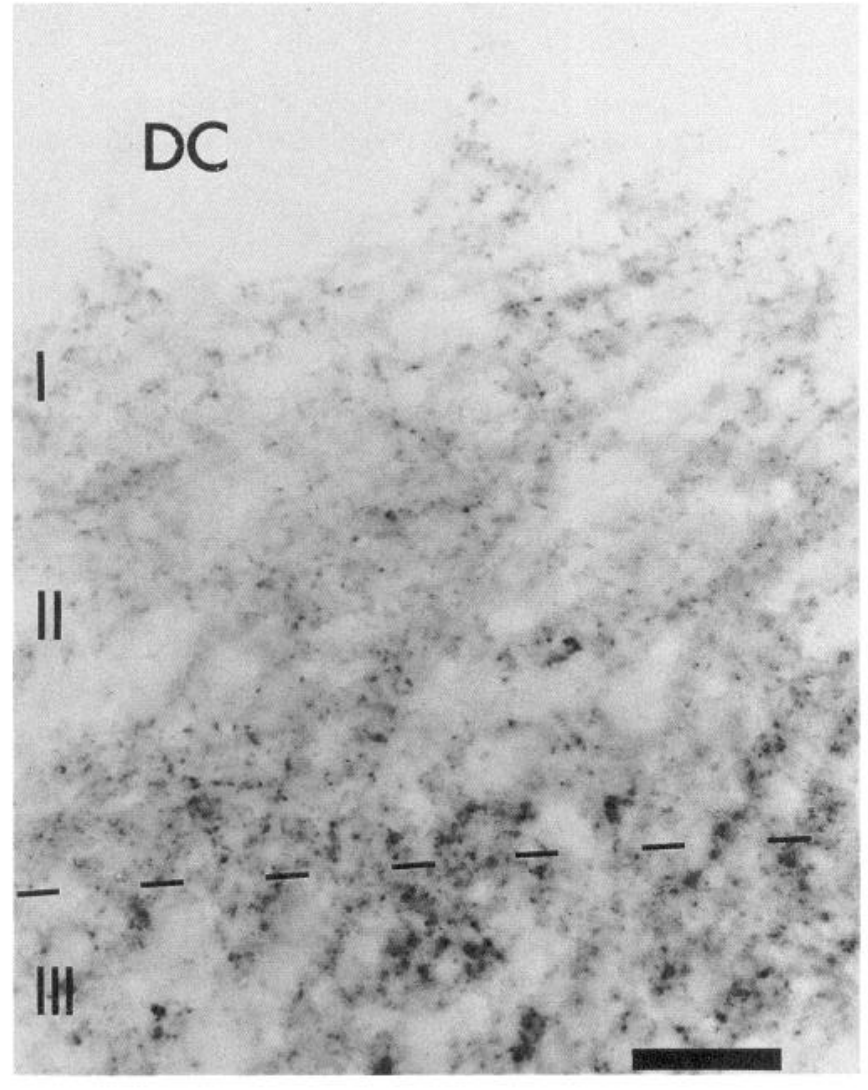

Figure 1. Light microscopic appearance of glycine receptor-LI in a transverse section of the superficial dorsal horn. There is no staining in the dorsal columns $(D C)$, a moderate density in lamina I and the dorsal part of lamina II, and a high density near the border between laminae II and III (dashed line). Scale bar, $20 \mu \mathrm{m}$.

a postembedding method to demonstrate GABA-LI, in order to examine the possible coexistence of GABA and glycine within presynaptic structures in the dorsal horn.

\section{Materials and Methods}

Tissue preparation. Ten adult Albino Swiss rats of either sex (190-230 gm) were deeply anesthetized and perfused with fixative according to one of the following protocols: (1) For light microscopy of glycine receptor-LI, two rats were fixed with $4 \%$ formaldehyde and the $L 4$ spinal segment was stored in the same fixative for $2 \mathrm{hr}$ before being rinsed and cryoprotected in $30 \%$ sucrose. The tissue was then cut into $16 \mu \mathrm{m}$ transverse sections with a cryostat. (2) For electron microscopy of glycine receptor-LI, five rats were perfused with a fixative containing $4 \%$ formaldehyde and $0.05 \%$ or $0.1 \%$ glutaraldehyde and the L4 segments were stored overnight in $4 \%$ formaldehyde, before being rinsed and sectioned at $60 \mu \mathrm{m}$ with a Vibratome in the transverse plane. (3) For combined pre- and postembedding immunocytochemistry, three rats were perfused with $1 \%$ formaldehyde, $1 \%$ glutaraldehyde and the L4 segment was stored in the same fixative for $2 \mathrm{hr}$ before being rinsed and cut into $60 \mu \mathrm{m}$ transverse sections with a Vibratome. All fixatives were made up in $0.1 \mathrm{~m}$ phosphate buffer. The Vibratome sections from animals for which glutaraldehyde had been present in the fixative were treated with $1 \%$ sodium borohydride in phosphate-buffered saline (PBS) for $30 \mathrm{~min}$ to quench free aldehyde sites (Kosaka et al., 1986), and then rinsed extensively in PBS.

Preembedding immunoctyochemistry. Vibratome sections from all animals were reacted with monoclonal antibody to glycine receptor $(\mathrm{mAb}$ 7a; Pfeiffer et al., 1984), which was obtained from a commercial source (Boehringer). The sections were incubated overnight in primary antibody diluted 1:500-12,000 in PBS containing $1 \%$ normal goat serum, and then processed by the avidin-biotin method (ABC Elite kit, Vector) according to the manufacturer's instructions. Peroxidase activity was visualized by using diaminobenzidine. In the case of sections that were for light microscopy, $0.3 \%$ Triton X-100 was added to the primary and secondary antibodies, and after the reaction the sections were dehydrated, cleared, and coverslipped. Sections that were for electron microscopy were reacted without the addition of Triton, and after the reaction the sections were treated with $1 \%$ osmium tetroxide for $20 \mathrm{~min}$ before being dehydrated in acetone and flat-embedded in Durcupan resin. Ultrathin sections were cut with a diamond knife and collected on copper mesh grids (for direct examination) or nickel mesh grids coated with Formvar (for subsequent postembedding immunocytochemistry). The sections in the first group were lightly stained with uranyl acetate and lead citrate, since it was found that heavier staining obscured the preembedding reaction product. Control Vibratome sections were treated according to the same immunocytochemical procedure, except that the primary antibody was replaced with PBS. This resulted in a complete absence of staining.

In material prepared for electron microscopy the border between laminae II and III could be readily detected because myelinated axons are rare in the ventral part of lamina II and common in lamina III. In material for light microscopy the position of the border between these laminae was determined with reference to other, osmicated sections.

Postembedding immunocytochemistry. This was carried out by the method of Holstege (1991) on ultrathin sections obtained from tissue that had been reacted with $\mathrm{mAb} 7 \mathrm{a}$ diluted 1:4000-12,000. Briefly, grids were placed for $1 \mathrm{hr}$ on a droplet of PBS containing $0.1 \%$ Triton X-100 (PBST), stored overnight at $4{ }^{\circ} \mathrm{C}$ on droplets of GABA antiserum diluted 1:5000-40,000 in PBST, rinsed, and incubated for $2 \mathrm{hr}$ with goat antirabbit IgG coupled to colloidal gold $(10 \mathrm{~nm}$; Seralab or Biocell) diluted $1: 25$. The sections were lightly stained with uranyl acetate and lead citrate. Control sections for the postembedding reaction were treated in the same way, except that the GABA antiserum was incubated with GABA conjugated to bovine serum albumen for $1 \mathrm{hr}$ before this was applied to the sections. The conjugate was made by the method of StormMathisen et al. (1983) and $0.1 \mu \mathrm{l}$ was added to $50 \mu \mathrm{l}$ of diluted antiserum $(1: 16,000)$. This abolished specific staining. The GABA antiserum (GABA-9; Hodgson et al., 1985) was a gift from Dr. P. Somogyi (University of Oxford).

In order to confirm the consistency of immunogold labeling, each structure of interest was examined on two sections in the series. For axons that were heavily labeled, no further analysis was needed. For structures that were lightly labeled, the density of gold grains over the profile was determined by measuring its sectioned area with a planimeter. In addition, the density of gold grains was measured over the nearest axon that formed asymmetric synapses. Since these axons are thought not to contain GABA, this latter value was taken as the background level. If the density of gold grains in the profile of interest exceeded this background level by at least a factor of 3 on both sections, the profile was considered to be GABA immunoreactive (Beaulieu and Somogyi, 1991).

Figure 2. Glycine receptor-LI at axodendritic and axosomatic synapses in laminae I-III. $a$, A large axon terminal $(A)$ containing several mitochondria and flattened synaptic vesicles is presynaptic to a dendritic shaft $(D)$ in lamina III. Immunoreaction product is present on the postsynaptic side (arrow). $b$, A dendrite $(D)$ in the dorsal part of lamina II receives an immunoreactive synapse from a profile $(A)$ that is probably an axon, as well as two nonimmunoreactive asymmetric synapses (arrowheads). Note the limited spread of reaction product at the immunoreactive synapse (arrow). $c$, A cell body in lamina I is postsynaptic at two immunoreactive axosomatic synapses (arrows) from boutons $A_{1}$ and $A_{2}$. Part of the nucleus $(N)$ can be seen. $d$, A dendritic shaft $(D)$ located near the border between laminae I and II is postsynaptic at two immunoreactive synapses (arrows). Both of the presynaptic axons $\left(A_{1}\right.$ and $\left.A_{2}\right)$ contain some dense-cored vesicles. $e$, A large dendritic shaft $(D)$ near the border between laminae II and III is postsynaptic at five immunoreactive synapses (arrows). Scale bars: $a-d, 0.5 \mu \mathrm{m} ; e, 1 \mu \mathrm{m}$. 

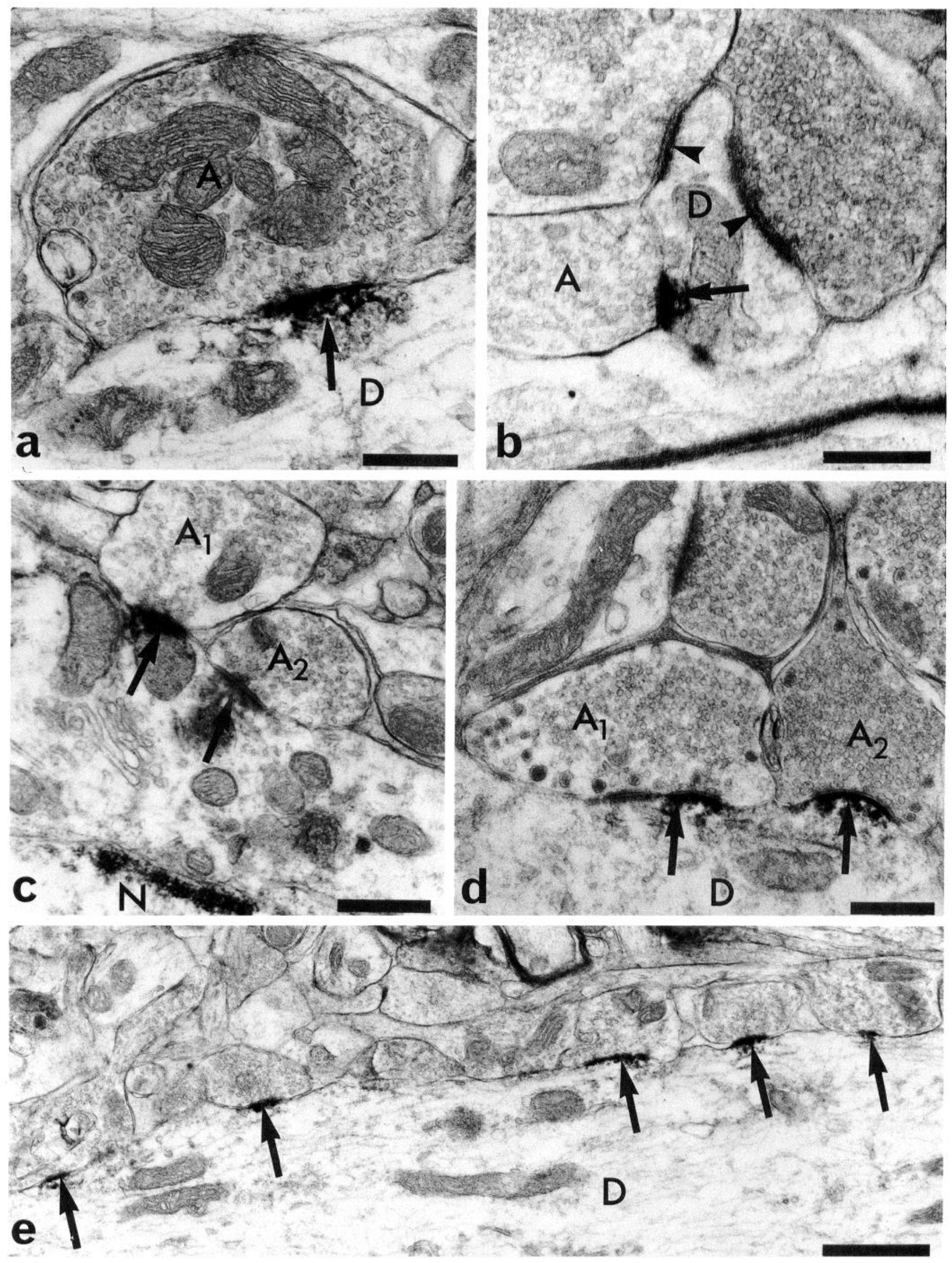

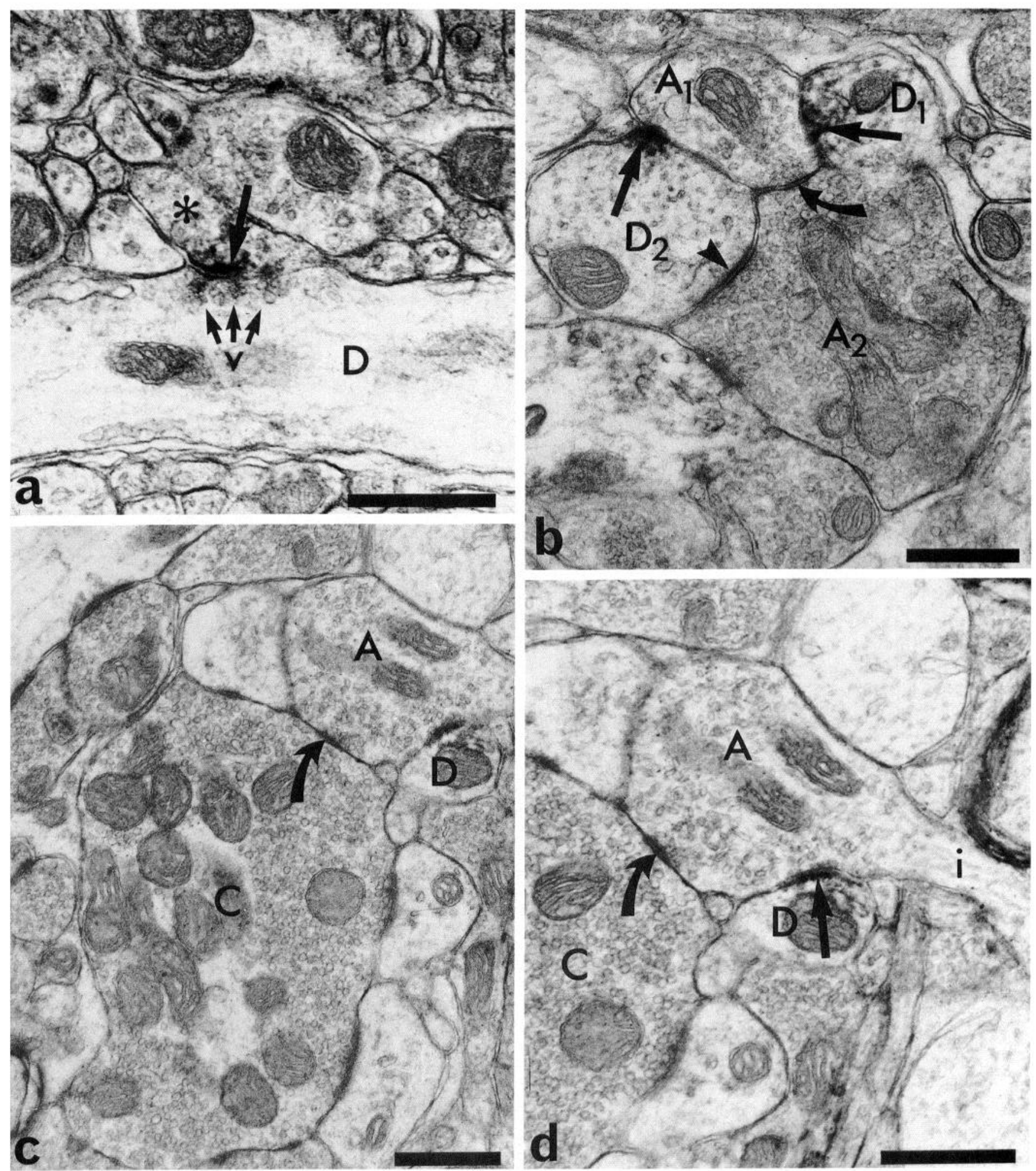

Figure 3. a, A dendritic shaft $(D)$ in lamina II contains a cluster of synaptic vesicles $(v)$ and forms an immunoreactive synapse (arrow) onto a small profile $\left(^{*}\right)$ that may be a dendritic spine. $b$, A small profile that is probably an axon $\left(A_{t}\right)$ near the border between laminae II and III forms glycine receptor-immunoreactive synapses (at straight arrows) onto two dendrites $\left(D_{1}\right.$ and $\left.D_{2}\right)$. In addition, it forms a nonimmunoreactive synapse onto axon $A_{2}$, which itself is presynaptic at an asymmetric synapse (arrowhead) onto dendrite $D_{2}$. The relationship between $A_{1}, A_{2}$, and $D_{2}$ constitutes a synaptic triad. $c$, A type II synaptic glomerulus in lamina II consists of a central axon $(C)$ and several peripheral profiles, including an axon $(A)$ that contains flattened vesicles and forms a nonimmunoreactive axoaxonic synapse onto the central axon (at curved arrow). $d$, When the section is photographed after tilting, an immunoreactive axodendritic synapse between axon $A$ and a small dendrite $(D)$ can be identified (straight arrow). An intervaricose portion of the axon can also be seen $(i)$. Scale bars, $0.5 \mu \mathrm{m}$. 

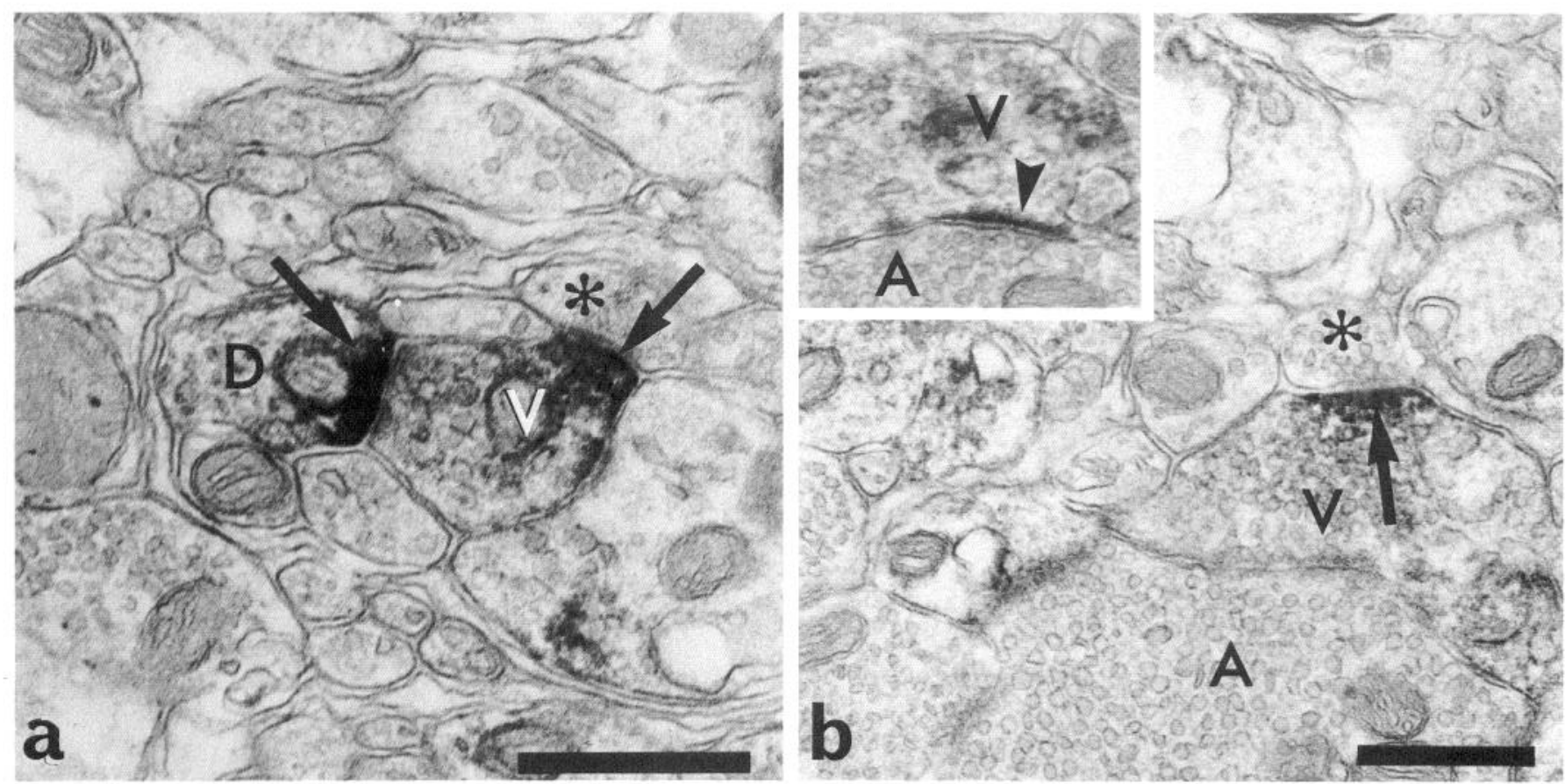

Figure 4. Glycine receptor-LI reaction product in profiles that contain vesicles in lamina II. $a$, A small profile $(V)$ is postsynaptic to a tiny structure containing vesicles $\left({ }^{*}\right)$ at an immunoreactive synapse (arrow). The profile $V$ contains a few rounded vesicles, and is itself presynaptic to a small dendrite $(D)$ at another immunoreactive synapse (arrow). $b$, A profile $(V)$ is postsynaptic to a small axon $(*)$ at an immunoreactive synapse $($ arrow) and contains rounded vesicles. In a nearby section (inset), $V$ is postsynaptic to a large axon $(A)$ at an asymmetric synapse (arrowhead). Scale bars, $0.5 \mu \mathrm{m}$.

\section{Results}

\section{Light microscopy}

Punctate staining was present throughout the gray matter of the spinal cord, but was not evenly distributed. In the dorsal horn, the density of staining was low in lamina I and the outer part of lamina II (Fig. 1), high in the ventral part of lamina II and in lamina III, and moderate throughout the remainder of the dorsal horn.

\section{Electron microscopy}

Glycine receptor immunoreactivity. The electron-dense reaction product was restricted to the postsynaptic element at certain synapses. In material from animals fixed with the lower concentration of glutaraldehyde, the optimal concentration of primary antibody was found to be 1:4000, and at this concentration the reaction product showed little spread away from the synapse, although its extension into the cytoplasm had an irregular edge and there was some staining of microtubules and outer mitochondrial membranes (Fig. 2). It was possible to distinguish the preembedding reaction product from the postsynaptic densities at asymmetric synapses, because the latter were somewhat less electron dense, were of uniform thickness when the synapse was orientated at right angles to the plane of section, and never extended onto adjacent structures such as mitochondria or microtubules. If necessary, obliquely sectioned synapses were tilted with a goniometer in order to allow definite identification.

Immunoreactive synapses were present throughout the superficial three laminae, but were more frequent in the ventral part of lamina II and in lamina III. The presynaptic elements at these synapses usually contained flattened or oval vesicles (Fig. $2 a-c$ ), although in some cases the vesicles were round (Fig.
$2 d$ ). At a few immunoreactive synapses in lamina I and the dorsal part of lamina II, the presynaptic profile contained several dense-cored vesicles as well as agranular ones (Fig. $2 d$ ). In most cases, the vesicles occupied much of the presynaptic profile, and these elements were therefore identified as axonal boutons. Sometimes an intervaricose portion could be seen emerging from the presynaptic structure (Fig. $3 d$ ). In all three laminae, the postsynaptic targets of these synapses were usually dendrites (Fig. $2 a, b, d, e$ ), although immunoreactive axosomatic synapses were also observed (Fig. $2 c$ ). Dendritic shafts cut in longitudinal section were sometimes postsynaptic at several immunoreactive synapses (Fig. 2e). It was not possible to determine whether immunoreactive synapses were symmetric or asymmetric, since the postsynaptic membrane was coated with reaction product at the presumed active site.

In lamina II, dendritic shafts were sometimes presynaptic at immunoreactive synapses. These could be identified because of their characteristic appearance: they contained mitochondria and microtubules as well as a small cluster of vesicles lying close to the presynaptic membrane. In transverse sections of the spinal cord, most presynaptic dendritic shafts were cross-sectioned, but some were cut along their long axis (Fig. $3 a$ ). The postsynaptic profiles at these synapses resembled dendritic shafts or spines and these therefore constituted dendrodendritic synapses. On rare occasions, reaction product was observed inside small structures that also contained vesicles (Fig. 4). These were also restricted to lamina II, and the vesicles, which were usually rounded, often did not fill the profile. Sometimes these structures were themselves presynaptic at immunoreactive synapses (Fig. $4 a$ ) or else were postsynaptic at asymmetric synapses (Fig. $4 b$ ).

Numerous synaptic glomeruli belonging to type I or type II of Ribeiro-da-Silva and Coimbra (1982) were found in laminae 

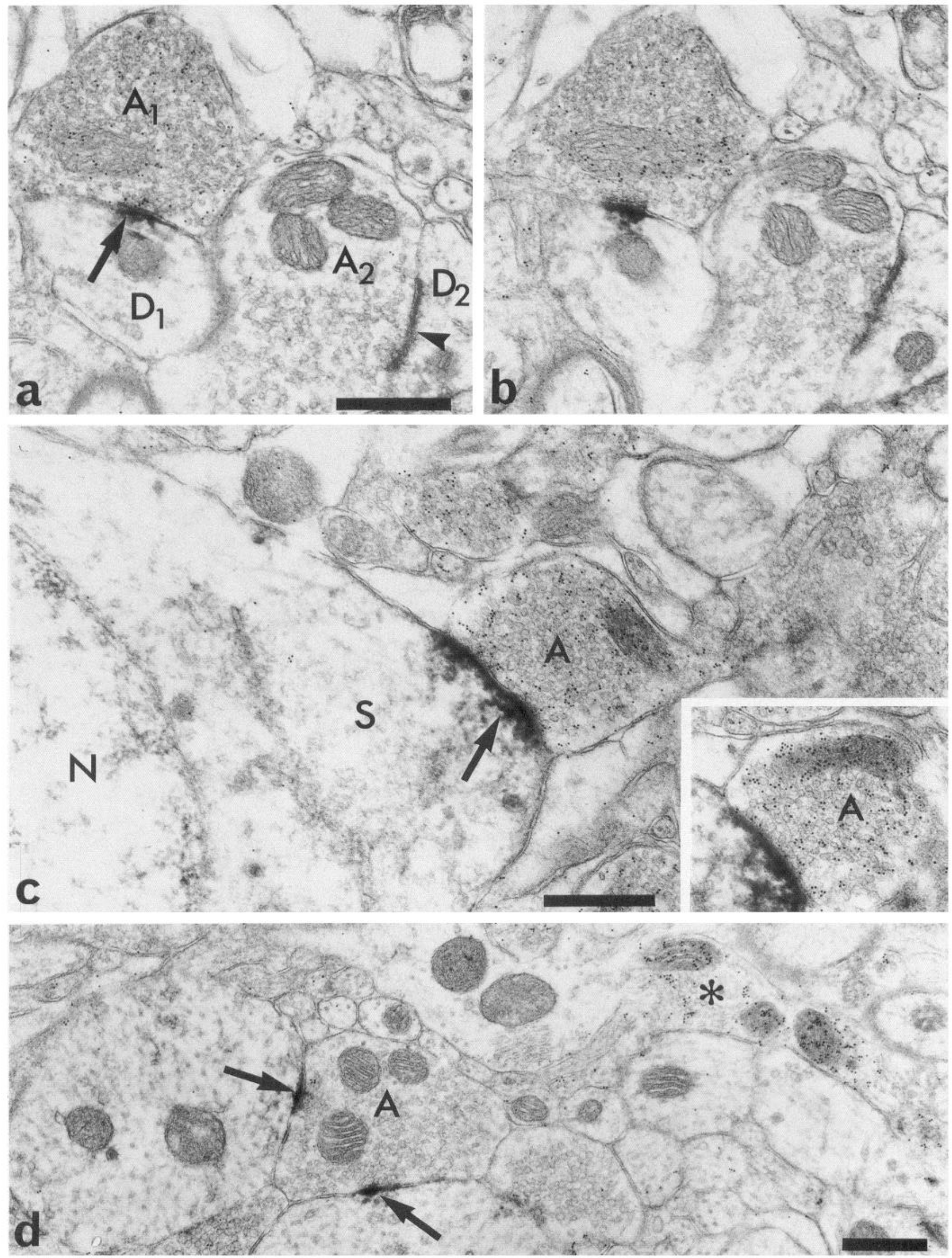
II and III. These could be distinguished on the basis of differences in their central axons. Those of type I glomeruli were relatively small and electron dense, and contained closely packed vesicles with highly variable diameters, whercas the central axons of type II glomeruli were larger and more electron lucent, and contained vesicles that were of more regular size. The central axons in these glomeruli never contained reaction product; however, on several occasions a peripheral axon (containing flattened vesicles) associated with a type II glomerulus formed one or more axodendritic synapses that were immunoreactive, as well as an axoaxonic synapse (onto the central axon) that was not (Fig. $3 c, d$ ). A similar arrangement was also observed with other axons that were not in synaptic glomeruli; these received a nonimmunoreactive axoaxonic synapse from an axon with flattened vesicles that also formed one or more immunoreactive axodendritic synapses (Fig. $3 b$ ). In these cases the axon that was postsynaptic at the axoaxonic synapse often formed an asymmetric synapse onto the dendrite that was postsynaptic at the immunoreactive synapse, and this therefore constituted a synaptic triad (Fig. 3b). Reaction product was never observed in vesicle-containing profiles that formed asymmetric synapses.

$G A B A-L I$. In sections that had been reacted with GABA antiserum by the postembedding method, GABA-LI was represented by colloidal gold particles, which were quite distinct from the diffuse reaction product associated with glycine receptor-LI (Figs. 5, 6). Heavy gold labeling was present over certain axons and these could often be seen to form symmetric synapses. Moderate labeling was seen over some dendrites and cell bodies, while axons that formed asymmetric synapses (including the central axons of synaptic glomeruli) were not labeled. Analysis of serial sections showed that the labeling of particular structures was quite consistent from section to section (Figs. 5a-c, 6). Glycine receptor reaction product was still readily observed, despite the higher concentration of glutaraldehyde present in the fixative, and indeed in this tissue the glycine receptor antibody could be used at concentrations as low as 1:12,000.

At many of the axodendritic and axosomatic synapses where glycine receptor-LI was present, the presynaptic axon was GABA immunoreactive (Fig. $5 a-c$ ), and these arrangements were seen in all three laminae. However, a few of the profiles that were presynaptic at glycine receptor-immunoreactive synapses did not show GABA-LI, despite being surrounded by axons that were strongly labeled with GABA antiserum (Fig. $5 d$ ). No ultrastructural differences between these two groups of axons were observed. Four examples of glycine receptor-immunoreactive, dendrodendritic synapses were seen, and in each case the presynaptic dendrite was GABA immunoreactive (Fig. $6 a, b$ ). In addition, in four cases a GABA-immunoreactive axon was seen to form an axodendritic synapse that was glycine receptor immunoreactive and an axoaxonic synapse that was not (Fig. $6 c, d$ ). In all of these latter arrangements, the second axon was not GABA immunoreactive, and in two of the four it was also presynaptic to the dendrite, thus forming a synaptic triad (Fig. $6 c, d)$.

\section{Discussion}

The monoclonal antibody $(\mathrm{mAb} 7 \mathrm{a})$ that was used in the present study detects a $93 \mathrm{kDa}$ protein component of the inhibitory glycine receptor (Pfeiffer et al., 1984). This component is not a membrane-spanning subunit, but is located on the cytoplasmic side of the postsynaptic membrane at presumed glycinergic synapses (Langosch et al., 1990) and is thought to anchor the receptor complex to the synaptic site, possibly by binding to tubulin (Kirsch et al., 1991). Although it has not been proved that glycine acts as a transmitter at all glycine receptor-immunoreactive synapses, there is some evidence that at least within the spinal cord this is generally the case. The laminar distribution of glycine receptor immunoreactivity is similar to the punctate staining seen with antisera to fixed glycine, which corresponds mainly to glycine-enriched axonal boutons (Todd, 1990). Both types of immunoreactivity are present in relatively small amounts in laminae I and II, but are more densely distributed in deeper laminae (Araki et al., 1988; Basbaum, 1988; van den Pol and Gorcs, 1988; Todd and Sullivan, 1990). This is quite different from the distribution of GABA or GAD immunoreactivities, which are strongest in laminae I-III and much weaker in deeper laminae (McLaughlin et al., 1975; Magoul et al., 1987; Todd and McKenzie, 1989). At the ultrastructural level, immunoreactivity observed with $\mathrm{mAb} 7 \mathrm{a}$ is restricted to the postsynaptic region at certain synapses, and does not show significant extension to nonsynaptic regions of membrane (unlike $\mathrm{GABA}_{\mathrm{A}}$ receptor immunoreactivity; Somogyi et al., 1989). The presynaptic structures at these immunoreactive synapses usually contain flattened or oval vesicles (Triller et al., 1985, 1987; present observations) and it has been shown that similar vesicles are generally present in glycine-immunoreactive synapses in the spinal cord (van den Pol and Gorcs, 1988; Holstege and Bongers, 1991).

There is evidence from studies of cerebellum that mAb $7 \mathrm{a}$ does not show detectable cross-reactivity with GABA receptors. Triller et al. (1987) found that immunostaining with this antibody did not occur at synapses between the axons of basket cells and Purkinje cell bodies, which are known to be GABAergic. It has since been shown that $\mathrm{GABA}_{\mathrm{A}}$ receptor immunoreactivity within cerebellum shows extensive spread beyond synaptic sites (Somogyi et al., 1989), which is quite different from the punctate distribution seen with $\mathrm{mAb}$ 7a (Triller et al., 1987).

\section{Glycinergic synapses within laminae I-III}

Basbaum (1988) examined the distribution of glycine receptorLI in rat spinal cord with two monoclonal antibodies, $7 \mathrm{a}$ (as used in the present study) and $2 \mathrm{~b}$, which recognizes the $48 \mathrm{kDa}$ $\alpha$-subunit. In agreement with other reports, he found that there

Figure 5. Combined preembedding immunostaining with antibody to glycine receptor and postembedding immunogold staining with antiserum to GABA. $a$, An axon $A_{l}$ in the ventral part of lamina II is presynaptic to a dendrite $\left(D_{t}\right)$ at a glycine receptor-immunoreactive synapse (arrow). $A_{i}$ has numerous gold grains over it, representing GABA-LI. Another axon $\left(A_{2}\right)$ forms an asymmetric synapse $($ arrowhead $)$ with a dendrite $\left(D_{2}\right)$, and this axon is not GABA immunoreactive. $b$. This is an adjacent ultrathin section, to show the consistency of immunogold staining with GABA antiserum. $C$, A cell body $(S)$ in lamina II is postsynaptic at an immunoreactive axosomatic synapse (arrow) to a GABA-immunoreactive axon $(A)$. Part of the nucleus $(N)$ can be seen. The inset shows the synapse in a nearby section. $d$, An axonal bouton $(A)$ that contains flattened vesicles is presynaptic at two immunoreactive axodendritic synapses (arrows). It has very few gold grains over it, despite heavy gold labeling of a nearby axon $\left.{ }^{*}\right)$. Scale bars, $0.5 \mu \mathrm{m}$. 

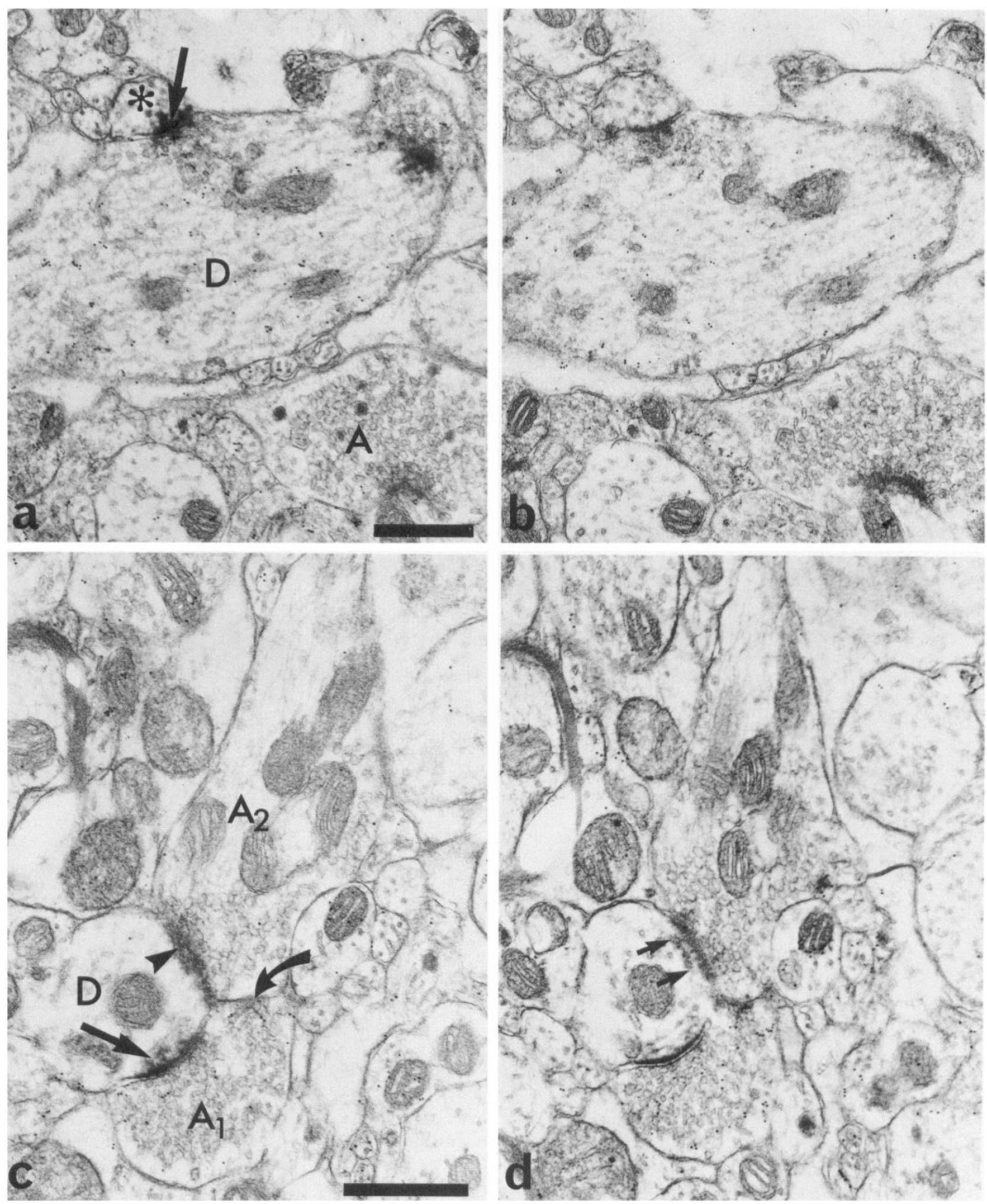

Figure 6. a A dendritic shaft $(D)$ in lamina II forms a glycine receptor-immunoreactive synapse (arrow) onto a small profile that is probably a dendrite $\left(^{*}\right)$. The dendrite $D$ contains some gold grains and is therefore moderately immunoreactive with GABA antiserum, whereas a nearby axon $(A)$ contains very few gold grains. $b$, A nearby section shows the consistency of immunogold labeling. $c$, An axon $\left(A_{t}\right)$ contains a significant density of gold grains, and is therefore GABA immunoreactive. It forms a glycine receptor-immunoreactive synapse (straight arrow) onto a dendrite $(D)$ and a nonimmunoreactive axoaxonic synapse (curved arrow) onto another axon $\left(A_{2}\right)$ that is not GABA-immunoreactive. $A_{2}$ forms an asymmetric synapse (arrowhead) onto $D$, which is sectioned obliquely. $d$, In the adjacent section, the same distribution of immunogold label can be seen, and subsynaptic dense bodies are visible (between small arrows). Scale bars, $0.5 \mu \mathrm{m}$. 
was strong immunoreactivity in deeper laminae of the dorsal horn (III-V), but he observed a complete absence of immunostaining in laminae I and II with both antibodies. The presence of light immunostaining in laminae I and II observed in the present study (Fig. 1) is in good agreement with the reports of Araki et al. (1988) and van den Pol and Gorcs (1988). In addition, we were able to confirm that the immunoreactivity present in these laminae was associated with synapses, and that these closely resembled immunoreactive synapses in lamina III. Taken together with the finding of glycine-immunoreactive axonal boutons and presynaptic dendrites in laminae I and II (Todd, 1990), the present results strongly suggest that glycine does function as an inhibitory neurotransmitter within the most superficial part of the dorsal horn, although there are apparently fewer glycinergic synapses than in deeper laminae.

The ultrastructural findings in the present study support the hypothesis that glycine acts as a transmitter at many axodendritic and axosomatic synapses within laminae I-III of the dorsal horn (Todd, 1990), and are entirely consistent with its role in producing postsynaptic inhibition (Wcrman ct al., 1968). In agreement with previous reports (e.g., Matus and Dennison, 1971; van den Pol and Corcs, 1988; Holstege and Bongers, 1991), we found that the presynaptic axons at these synapses usually contained flattened agranular vesicles. In a few cases the presynaptic axon contained significant numbers of dense-cored vesicles, and this suggests that glycine may coexist with one or more neuropeptides in these axons, since these peptides are thought to be located in dense-cored vesicles within the superficial dorsal horn (Merighi et al., 1989). Although the origins of the dendrites that were postsynaptic at immunoreactive synapses cannot be determined, it appears likely that neurons in each of laminae I-III receive a glycinergic input, since immunoreactive axosomatic synapses were observed in each lamina. The presence of numerous immunoreactive synapses on certain dendrites in this region (Fig. $2 e$ ) suggests that some dorsal horn neurons are subject to very powerful postsynaptic inhibition by glycine.

Some of the immunoreactive synapses in this study could be identified as dendrodendritic, since the presynaptic element was clearly a dendritic shaft (Figs. $3 a, 6 a, b)$. The frequency of these synapses was probably underestimated, since dendritic spines and small dendritic shafts containing many vesicles cannot be reliably distinguished from axonal boutons in random sections. We have previously identified glycine-LI in presynaptic dendrites in this region (Todd, 1990) and shown that some of these are derived from islet cells that possess both glycine-LI and GABA-LI (Spike and Todd, 1992). Taken together with the present findings, this suggests that glycine is present in high concentrations in certain presynaptic dendrites and acts as a transmitter at some dendrodendritic synapses.

\section{Coexistence of GABA and glycine}

In order to compare the distribution of glycine receptor with GABA, we carried out postembedding immunocytochemistry with an antiserum that recognizes glutaraldehyde-fixed GABA (Hodgson et al., 1985). This was possible because the reaction products of the two immunocytochemical techniques are easily distinguished, and because glycine receptor-LI survives fixation with the higher concentration of glutaraldehyde that is necessary for the GABA immunostaining. We have previously shown that glycine-LI and GABA-LI coexist in many neurons in laminae I-III (Todd and Sullivan, 1990), and since cells in these laminae often have extensive local axonal arborizations, it was expected that the two transmitters would be present in the same axonal boutons. Although the present results do not show this directly, the fact that many presynaptic axons at glycinc rcceptor-immunoreactive synapses showed GABA-LI (Figs. 5, $6 c, d$ ) strongly suggests that both GABA and glycine are present in these boutons. A similar arrangement has been observed in the spinal ventral horn, where GAD-immunoreactive boutons were presynaptic at glycine receptor-immunoreactive synapses (Triller et al., 1987), and direct immunocytochemical evidence for coexistence of GABA and glycine has been obtained for axonal boutons in the cerebellum by Ottersen et al. (1988).

Some axons that were presynaptic at glycine receptor-immunoreactive synapses did not show GABA-LI (Fig. 5d). Since virtually all glycinergic neurons in laminae I-III appear to contain GABA (Todd and Sullivan, 1990), it is possible that these axons are derived from neurons in deeper laminae or else from glycinergic neurons in the brain (which are known to project to the ventral horn; Holstege and Bongers, 1991). Alternatively, these axons may have contained a low concentration of GABA that could not be detected by the postembedding immunocytochemical method used here. Presynaptic dendrites that formed glycine receptor-immunoreactive synapses could contain GABA, which agrees with the finding that islet cells in lamina II with both types of immunoreactivity can possess presynaptic dendrites (Spike and Todd, 1992).

Axons that were GABA immunoreactive and formed glycine receptor-immunoreactive synapses were presynaptic at axodendritic, axosomatic, and axoaxonic synapses within these laminae. Ribeiro-da-Silva and Cuello (1990) observed similar synaptic arrangements in this region formed by axons that were immunoreactive with antibody to ChAT, which is a marker for cholinergic structures. There is immunohistochemical evidence that, in lamina III, ACh is present in neurons that contain GABA but do not have elevated levels of glycine (Kosaka et al., 1988; Todd, 1991). If it is assumed that the majority of the axons containing these three transmitters are derived from dorsal horn neurons, then it would appear that GABAergic neurons in this region that are glycine immunoreactive have similar synaptic connections to those that contain $\mathrm{ACh}$.

\section{Glycine in axoaxonic synapses}

Glycine receptor-LI was very occasionally seen in profiles that contained vesicles in lamina II (Fig. 4). Although it is possible that some of these were axons, their appearance and synaptic connections both suggested that they were presynaptic dendrites. They contained round vesicles of variable sizes that were not densely packed, and they thus resembled the " $V_{2}$ " profiles of Ribeiro-da-Silva and Coimbra (1982), which were identified by those authors as presynaptic dendrites. In addition, they were sometimes postsynaptic at asymmetric synapses, and this arrangement is common for presynaptic dendrites in rat dorsal horn.

Many examples of typical axoaxonic synapses were seen, particularly in the ventral part of lamina II and in lamina III (Ralston, 1979). Glycine receptor-LI was never seen in association with these synapses, although the presynaptic axons often formed axodendritic synapses that were immunoreactive (Fig. 3b-d) and these axons could also possess GABA-LI (Fig. $6 c, d$ ). This agrees with the results of a preembedding immunocytochemical study with antiserum to glycine (Todd, 1990), in which the presynaptic axons at axoaxonic synapses were frequently im- 
munoreactive. Taken together, these results strongly suggest that at some axoaxonic synapses in laminae II and III, the presynaptic axons contain both GABA and elevated levels of glycine.

Axoaxonic synapses are generally believed to be the anatomical substrate for presynaptic inhibition. While there is a great deal of pharmacological evidence that GABA can generate this type of inhibition, studies with strychnine (a glycine receptor antagonist) have failed to indicate a role for glycine (reviewed by Levy, 1977). There are two possible explanations for the failure to detect glycine receptor immunoreactivity at axoaxonic synapses in the present study: either glycine acts at a different type of receptor that does not possess the $93 \mathrm{kDa}$ component and is therefore not recognized by $\mathrm{mAb} 7 \mathrm{a}$, or else it does not act as a neurotransmitter at axoaxonic synapses. In support of the first explanation, Furuyama et al. (1992) have recently demonstrated that many of the large neurons in rat dorsal root ganglion contain mRNA for the $\beta$-subunit of the glycine receptor, and this subunit may therefore be present at the central terminals of these axons within the dorsal horn. It has been suggested that the $\beta$-subunit may form atypical glycine receptors at which strychnine is not effective (Malosio et al., 1991), and this would therefore be compatible with glycine having a presynaptic inhibitory effect that would not have been detected in studies with strychnine (Levy, 1977). However, the $\beta$-subunit is widely expressed in the CNS, and is synthesized in regions such as hippocampus (Malosio et al., 1991), where glycine-immunoreactive axon terminals do not appcar to be present (Wenthold et al., 1987). It is therefore possible that this subunit may be present in arrangements other than the inhibitory glycine receptor. If the second explanation is correct, then it is presumably GABA, which would be released with glycine, that acts at axoaxonic synapses to produce presynaptic inhibition, while both transmitters cause postsynaptic inhibition at axodendritic synapses. If this is so, then this would provide an example of a neurotransmitter being released at a synapse at which it is ineffective. Whichever of these explanations is correct, it appears that glycine does not act at the same type of receptor at axoaxonic synapses as those that are involved in axodendritic and axosomatic ones. The differential distribution of postsynaptic receptors at different types of synapse may cast some light on the question of why certain presynaptic axons contain more than one neurotransmitter (Osen et al., 1990).

\section{References}

Aprison MH, Werman R (1965) The distribution of glycine in cat spinal cord and roots. Life Sci 4:2075-2083.

Araki T, Yamano M, Murakami T, Wanaka A, Betz H, Tohyama M (1988) Localization of glycine receptors in the rat central nervous system: an immunocytochemical study using monoclonal antibody. Neuroscience 25:613-624.

Barber RP, Vaughn JE, Saito K, McLaughlin BJ, Roberts E (1978) GABAergic terminals are presynaptic to primary afferent terminals in the substanatia gelatinosa of the rat spinal cord. Brain Res 141: $35-55$.

Barker JL, Nicoll RA (1973) The pharmacology and ionic dependency of amino acid responses in the frog spinal cord. J Physiol (Lond) 228: 259-277.

Basbaum AI (1988) Distribution of glycine receptor immunoreactivity in the spinal cord of the rat: cytochemical evidence for a differential glycinergic control of lamina I and V nociceptive neurons. J Comp Neurol 278:330-336.

Beaulieu C, Somogyi P (1991) Enrichment of cholinergic synaptic terminals on GABAergic neurons and coexistence of immunoreactive GABA and choline acetyltransferase in the same synaptic terminals in the striate cortex of the cat. J Comp Neurol 304:666-680.
Campistron G, Buijs RM, Geffard M (1986) Glycine neurons in the brain and spinal cord. Antibody production and immunocytochemical localization. Brain Res 376:400-405.

Carlton SM, Hayes ES (1990) Light microscopic and ultrastructural analysis of GABA-immunoreactive profiles in the monkey spinal cord. J Comp Neurol 300:162-182.

Curtis DR, Hösli L, Johnston GAR (1968) A pharmacological study of the depression of spinal neurons by glycine and related amino acids. Exp Brain Res 6:1-18.

Furuyama T, Sato $M$, Sato $K$, Araki T, Inagaki S, Takagi $H$, Tohyama M (1992) Coexpression of glycine receptor $\beta$ subunit and $\mathrm{GABA}_{\mathrm{A}}$ receptor $\gamma$ subunit mRNA in the rat dorsal root ganglion cells. Mol Brain Res 12:335-338.

Hodgson AJ, Penke B, Erdei A, Chubb IW, Somogyi P (1985) Antisera to $\gamma$-aminobutyric acid. I. Production and characterization using a new model system. J Histochem Cytochcm 33:229-239.

Holstege JC (1991) Ultrastructural evidence for GABAergic brain stem projections to spinal motoneurons in the rat. J Neurosci 11:159-167.

Holstege JC, Bongers CMH (1991) A glycinergic projection from the ventromedial lower brainstem to spinal motoneurons. An ultrastructural double labeling study in the rat. Brain Res 566:308-315.

Hopkin JM, Neal MJ (1970) The release of $\left[{ }^{14} \mathrm{C}\right]$ glycine from electrically stimulated rat spinal cord slices. Br J Pharmacol 40:136-138.

Kirsch J, Langosch D, Prior P, Littauer UZ, Schmitt B, Betz H (1991) The 93-kDa glycine receptor-associated protein binds to tubulin. J Biol Chem 266:22242-22245.

Kosaka T, Nagatsu I, Wu JY, Hama K (1986) Use of high concentrations of glutaraldehyde for immunocytochemistry of transmitter synthesizing enzymes in the central nervous system. Neuroscience 19: 975-990.

Kosaka T, Tauchi M, Dahl JL (1988) Cholinergic neurons containing GABA-like and/or glutamic acid decarboxylase-like immunoreactivities in various brain regions of the rat. Exp Brain Res 70:605-617.

Langosch D, Betz H, Becker C-M (1990) Molecular structure and developmental regulation of the inhibitory glycine receptor. In: Glycine neurotransmission (Ottersen OP, Storm-Mathisen J, eds), pp 67 82. Chichester: Wiley.

Levy RA (1977) The role of GABA in primary afferent depolarization. Prog Neurobiol 9:211-267.

Magoul R, Onteniente B, Geffard M, Calas A (1987) Anatomical distribution and ultrastructural organization of the GABAergic system in the rat spinal cord. An immunocytochemical study using antiGABA antibodies. Neuroscience 20:1001-1009.

Malosio M-L, Marqueze-Pouey B, Kuhse J, Betz H (1991) Widespread expression of glycine receptor subunit mRNAs in the adult and developing rat brain. EMBO J 10:2401-2409.

Matus AI, Dennison ME (1971) Autoradiographic localization of tritiated glycine at "flat vesicle" synapses in spinal cord. Brain Res 32: 195-197.

McLaughlin BJ, Barber R, Saito K, Roberts E, Wu J-Y (1975) Immunocytochemical localization of glutamate decarboxylase in rat spinal cord. J Comp Neurol 164:305-322.

Merighi A, Polak JM, Fumagalli G, Theodosis DT (1989) Ultrastructural localization of neuropeptides and GABA in rat dorsal horn: a comparison of different immunogold labeling techniques. J Histochem Cytochem 37:529-540.

Neal MJ (1971) The uptake of $\left[{ }^{14} \mathrm{C}\right]$ glycine by slices of mammalian spinal cord. J Physiol (Lond) 215:103-117.

Osen KK, Ottersen OP, Storm-Mathisen J (1990) Colocalization of glycine-like and GABA-like immunoreactivities: a semiquantitative study of individual neurons in the dorsal cochlear nucleus of cat. In: Glycine neurotransmission (Ottersen OP, Storm-Mathisen J, eds), pp 417-452. Chichester: Wiley.

Ottersen OP (1989) Quantitative electron microscopic immunocytochemistry of neuroactive amino acids. Anat Embryol (Berl) 180:115.

Ottersen OP, Storm-Mathisen J (1987) Distribution of inhibitory amino acid neurons in the cerebellum with some observations on the spinal cord: an immunocytochemical study with antisera against fixed GABA, glycine, taurine and $\beta$-alanine. J Mind Behav 8:503-518.

Ottersen OP, Storm-Mathisen J, Somogyi P (1988) Colocalization of glycine-like and GABA-like immunorcactivitics in Golgi cell terminals in the rat cerebellum: a postembedding light and electron microscope study. Brain Res 450:342-353.

Pfeiffer G, Simler R, Greenigloh G, Betz H (1984) Monoclonal an- 
tibodies and peptide mapping reveal structural similarities between the subunits of the glycine receptor of the rat spinal cord. Proc Natl Acad Sci USA 81:7224-7227.

Ralston HJ (1979) The fine structure of laminae I, II and III of the macaque spinal cord. J Comp Neurol 184:619-642.

Ribeiro-da-Silva A, Coimbra A (1982) Two types of synaptic glomeruli and their distribution in laminae I-III (substantia gelatinosa Rolandi) of the rat spinal cord. J Comp Neurol 209:176-186.

Ribeiro-da-Silva A, Cuello AC (1990) Choline acetyltransferase-immunoreactive profiles are presynaptic to primary sensory fibres in the rat superficial dorsal horn. J Comp Neurol 295:370-384

Somogyi P, Takagi H, Richards JG, Mohler H (1989) Subcellular localization of benzodiazepine receptors in the cerebellum of rat, cat and monkey using monoclonal antibodies. J Neurosci 9:2197-2209.

Spike RC, Todd AJ (1992) An ultrastructural and immunocytochemical study of lamina II islet cells in rat spinal dorsal horn. J Comp Neurol 323:359-369.

Storm-Mathisen J, Leknes AK, Bore A, Vaaland JL, Edminson P, Haug FMS, Ottersen OP (1983) First visualisation of glutamate and GABA in neurons by immunocytochemistry. Nature (Lond) 301:517-520.

Todd AJ (1990) An electron microscope study of glycine-like immunoreactivity in laminae I-III of the spinal dorsal horn of the rat. Neuroscience 39:387-394.
Todd AJ (1991) Immunohistochemical evidence that acetylcholine and glycine exist in different populations of GABAergic neurons in lamina III of rat spinal dorsal horn. Neuroscience 44:741-746.

Todd AJ, Lochhead V (1990) GABA-like immunoreactivity in type I glomeruli of rat substantia gelatinosa. Brain Res 514:171-174.

Todd AJ, McKenzie J (1989) GABA-immunoreactive neurons in the dorsal horn of the rat spinal cord. Neuroscience 31:799-806.

Todd AJ, Sullivan AC (1990) Light microscope study of GABA-like and glycine-like immunoreactivities in the spinal cord of the rat. J Comp Neurol 296:496-505.

Triller A, Cluzeaud F, Pfeiffer F, Betz H, Korn H (1985) Distribution of glycine receptors at central synapses: an immunoelectron microscopy study. J Cell Biol 101:683-688.

Triller A, Cluzeaud F, Korn H (1987) Gamma-amino butyric acidcontaining synapses can be apposed to glycine receptors at central synapses. J Cell Biol 104:947-956.

van den Pol AN, Gorcs T (1988) Glycine and glycine receptor immunoreactivity in brain and spinal cord. J Neurosci 8:472-492.

Wenthold RJ, Huie D, Altschuler RA, Reeks KA (1987) Glycine immunoreactivity localized in the cochlear nucleus and superior olivary complex. Neuroscience 22:897-912.

Werman R, Davidoff RA, Aprison MH (1968) Inhibitory action of glycine on spinal neurons in the cat. J Neurophysiol 31:81-95. 